\title{
Silica Nanoparticles With Encapsulated DNA (SPED) to Trace the Spread of Pathogens in Healthcare
}

\section{Cinzia Ullrich}

University of Zurich Faculty of Medicine: Universitat Zurich Medizinische Fakultat

\section{Anne M Luescher}

ETH Zurich Department of Chemistry and Applied Biosciences: Eidgenossische Technische Hochschule Zurich Departement Chemie und Angewandte Biowissenschaften

\section{Julian Koch}

ETH Zurich Department of Chemistry and Applied Biosciences: Eidgenossische Technische Hochschule Zurich Departement Chemie und Angewandte Biowissenschaften

\section{Robert N Grass}

ETH-Zurich, Dept Chemistry and Applied Biosciences

Hugo Sax ( $\sim$ hugo.sax@mac.com )

Bern University Hospital https://orcid.org/0000-0002-1532-2198

\section{Research}

Keywords: Infection control, infection prevention, pathogen transmission, silica nanoparticles, surrogate markers

Posted Date: September 14th, 2021

DOI: https://doi.org/10.21203/rs.3.rs-870804/v1

License: (c) (1) This work is licensed under a Creative Commons Attribution 4.0 International License. Read Full License

Version of Record: A version of this preprint was published at Antimicrobial Resistance and Infection Control on January 10th, 2022. See the published version at https://doi.org/10.1186/s13756-021-010413. 
1 Silica nanoparticles with encapsulated DNA (SPED) to trace the spread of pathogens in

2 healthcare

3 Authors: Cinzia Ullrich (1)*, Anne M. Luescher (2)*, Julian Koch (2), Robert N. Grass (2)†,

4 Hugo Sax $(1,3) \dagger$

$5 *$ These authors contributed equally to this article as first authors.

$6 \uparrow$ These authors contributed equally to this article as last authors.

(1) Department of Infectious Diseases and Hospital Epidemiology, University Hospital Zurich, University of Zurich, Zurich, Switzerland

(2) Institute for Chemical and Bioengineering, Department of Chemistry and Applied Biosciences, ETH Zurich, Switzerland

(3) Department of Infectious Diseases, Bern University Hospital and University of Bern, Bern, Switzerland

Correspondence to:

Prof Hugo Sax, MD, Giessereistrasse 12, 8005 Zurich, Switzerland; email: hugo.sax@mac.com; phone: +41-79-309-3888

Prof. Dr. Robert Grass, Department of Chemistry and Applied Biosciences, ETH Zurich,

Vladimir-Prelog-Weg 1-5/10, 8093 Zurich, Switzerland; email: robert.grass@ chem.ethz.ch; phone: +41-44-633-6334

Keywords: Infection control, infection prevention, pathogen transmission, silica nanoparticles, surrogate markers 
Abstract (Word count: 350/350)

Background: To establish effective infection control protocols, understanding pathogen transmission pathways is essential. Non-infectious surrogate tracers may safely explore these pathways and challenge pre-existing assumptions. We used silica nanoparticles with encapsulated DNA (SPED) for the first time in a real-life hospital setting to investigate potential transmission routes of vancomycin-resistant enterococci in the context of a prolonged outbreak.

Methods: The two study experiments took place in the 900-bed University Hospital Zurich, Switzerland. A three-run 'Patient experiment' investigated pathogen transmission via toilet seats in a two-patient room with shared bathroom. First, various predetermined body and fomite sites in a two-bed patient room were probed at baseline. Then, after the first patient was contaminated with SPED at the subgluteal region, both patients sequentially performed a toilet routine. All sites were consequently swabbed again for SPED contamination. Eight hours later, further spread was tested at predefined sites in the patient room and throughout the ward. A two-run 'Mobile device experiment' explored the potential transmission by mobile phones and stethoscopes in a quasi-realistic setting. All SPED contamination statuses and levels were determined by real-time qPCR.

Results: Over all three runs, the 'Patient experiment' yielded SPED in 59 of $73(80.8 \%)$ predefined body and environmental sites. Specifically, positivity rates were $100 \%$ on subgluteal skin, toilet seats, tap handles, and entertainment devices, the initially contaminated patients' hands; $83.3 \%$ on patient phones and bed controls; $80 \%$ on intravenous pumps; $75 \%$ on toilet flush plates and door handles, and $0 \%$ on the initially not contaminated patients' hands. SPED spread as far as doctor's keyboards (66.6\%), staff mobile phones $(33.3 \%)$ and nurses' keyboards (33.3\%) after eight hours. The 'Mobile device experiment' resulted in 16 of $22(72.7 \%)$ positive follow-up samples, and transmission to the second patient occurred in one of the two runs. 
52 Conclusions: For the first time SPED were used to investigate potential transmission

53 pathways in a real hospital setting. The results suggest that, in the absence of targeted

54 cleaning, toilet seats and mobile devices may result in widespread transmission of pathogens

55 departing from one contaminated patient skin region.

56 


\section{Background}

Healthcare associated infections (HCAI) cause higher complication and mortality rates, prolonged hospital stays, and increased healthcare costs $(1,2)$. Moreover, the spread of antimicrobial resistant pathogens is considered one of the most crucial issues in healthcare (3).

Multiple large-scale outbreaks of vancomycin-resistant enterococci (VRE) in Swiss hospitals in the last decade indicate a surge of VRE in Switzerland (4-6). Poor hand hygiene $(\mathrm{HH})$ has proven to be a primary cause of pathogen transmission (7). Guidelines and protocols have been established to improve hand hygiene in healthcare $(2,8)$ with limited overall success $(9,10)$. Several studies published over the past 20 years indicate the effect of contaminated hospital environment on pathogen transmission - especially multi-resistant pathogens such as VRE (11-14). Pittet et al. (7) list "organisms shed onto inanimate objects immediately surrounding the patient" as the starting point of cross-transmission between patients. Other studies suggest that the risk for VRE acquisition is higher when a patient stays in a hospital room previously occupied by a VRE-infected patient (15-17). Lower rates of multi-drug resistant pathogen colonization and infection occur in hospitals with single-rooms and thus, individualized toilet use $(18,19)$.

Touching a VRE-contaminated surface carries a similar risk for pathogen-transmission on hands as touching a colonized patient even though the concentration of VRE on surfaces is much lower $(12,20,21)$. Randle et al. (22) found that HH compliance in HCW was $80 \%$ (adjusted odds ratio (aOR) 1.88, 95\% CI 1.15-3.07)) after direct patient contact, whereas HH was performed in only $50 \%$ (aOR $0.60,95 \%$ CI $0.38-0.93$ ) after contact with a patient's surroundings. In an observational study with head cameras during real-life active patient care Clack et al. even found a $\mathrm{HH}$ "adherence" of only $5 \%$ prior to potentially patient colonizing touch events and only $1 \%$ before possible infection events (e.g., before touching central line insertion sites, wounds, sterile needles) (10). 
It is not surprising that Cassone et al. (23) included toilet seats in an environmental panel as a proxy for patients with VRE colonization. Although many experts emphasize the transmission of pathogens from contaminated areas through the hands of healthcare workers (HCW), fewer recognize the effect of shared bathrooms or toilets as possible transmission hubs of multi-drug resistant microorganisms (24). The transmission pathway of pathogens, in particular VRE, through toilet seats has not yet been explicitly investigated.

The use of surrogate tracers allows to safely determine patient-to-patient-transmission of pathogens in real-life care-settings $(25,26)$. In the past, various pathogen surrogates have been used, including cauliflower mosaic virus DNA (27-31), bacteriophage MS-2 (29, 32, 33), non-toxigenic Clostridioides difficile spores (34), fluorescent agents (35), and lightreflecting chemical compounds combined with flashlight photography (33). Silica nanoparticles with encapsulated DNA (SPED) with known nucleotide sequences have been described by Paunescu et al. (36) (Annex Figure 1). They are used as inert tracers in biological product tagging, tracing of food, studying animal predator-prey-relationships, and characterizing aquifer and wastewater (37-40). As Scotoni et al. (25) have shown in a microbiology and a behaviour laboratory setting, that SPED represent promising surrogate tracers for microbial transmission in healthcare because SPED and bacteria share strong similarities in transmission, are non-toxic, and can be individually tagged (41).

In the current work, we aimed to investigate the spread of SPED as surrogates for pathogen transmission between patients in a real-world-scenario, involving the shared use of the toilet in a two-bed patient room. This investigation was clinically motivated by an ongoing VRE outbreak in our hospital in the course of which the risk of shared restroom use and necessary cleaning schedules became a topic of interest. 
107

\section{SPED and swab technique}

The synthesis and characterization of SPED followed the protocol of Paunescu et al. (36). We used the same three batches of SPED with individual DNA-tagging as previously described by Scotoni et al. (25), SPED-1 (218 \pm 80nm; DNA loading 21 $\mu \mathrm{g})$, SPED-2 (146.6 \pm

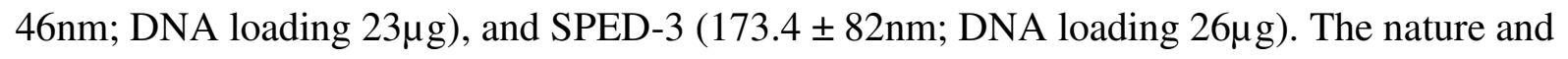
handling of SPED is described in detail in the Technical Appendix.

\section{Quantification of SPED and statistical analysis}

The procurance of exact SPED concentration levels based on real-time quantitative PCR (qPCR) cycle values is specified in the Technical Appendix. To evaluate the corresponding concentrations in $\mathrm{mg} / \mathrm{mL}$, all samples were compared with an experimentspecific threshold resulting from the SPED concentration of the baseline sample yielding the strongest qPCR signal and thus, the highest concentration of all baseline samples. This represents a conservative approach to adjust all results for background signals resulting from (cross-)contamination arising during experimental processing. Consequently, values with concentrations above threshold were considered as positive, values below as negative. The descriptive analysis was conducted with Microsoft Excel® 2020.

\section{Explorative experiments}

Before their use with patients, we chose to explore SPED for transmission characteristics in relation to the necessary amount and concentration in the restroom of an office building of the hospital campus in two controlled experiments.

First, $3 \mathrm{~mL}$ of a $1 \mathrm{mg} / \mathrm{mL}$ SPED suspension in ultrapure MilliQ water (type 1, 18.2M $\Omega \cdot \mathrm{cm}$ at $24^{\circ} \mathrm{C}$, Milli-Q®; Merck, Darmstadt, Germany) were deposited on bare skin at 
a subgluteal skin site of a voluntary 27 -year-old male participant and left to air-dry. The

130 participant was then asked to sit on the toilet seat for ten seconds, flush the toilet, and perform

131 handwashing after having left the restroom by using the door handle. The participant's

132 contaminated body site, toilet seat, toilet flush plate, door handle, and tap were swabbed

133 before and after this sequence. In a follow-up experiment, we verified the transmission of

134 SPED from a Participant-A, contaminated equally as described above, to Participant-B,

135 both subsequentially performing the same toilet use sequence as described above.

\section{Patient experiment}

The patient experiment took place in patient rooms on a haemato-oncological ward at the University Hospital Zurich, Switzerland, it was repeated three times (Run-1-Run-3) with a new SPED batch being used (SPED-1-SPED-3) for each run. Run-1 and Run-2 took place in the same, Run-3 in another patient room of similar layout (Figure 1). During the experiment, cleaning in the patient room was limited to floor wiping.

Any pair of patients in a two-bed room were eligible for the study if they both gave informed consent. They were conveniently chosen by ward staff and allowed to withdraw at any time without indicating a reason.

We pre-defined 20 swabbing sites dimensioned 1 x $3 \mathrm{~cm}, 16$ concerning fomites, of which eight were located inside, four in the restroom and four outside the patient room, and two body sites on each patient (Table 1). These swab sites were chosen following the idea of 'high-touch surfaces' according to Huslage et al. (42). Swabbing was performed as described in the Technical Appendix.

First, all sites were swabbed as negative controls. Then, we applied $3 \mathrm{~mL}$ of our SPED test suspension $(1 \mathrm{mg} / \mathrm{mL})$ to the subgluteal region of Patient-A by using a graduated pipette and a brush and left it to air-dry. A swab from the subgluteal swabbing sites of Patient-A taken immediately after contamination constituted the positive control. Consecutively, we 
154 asked Patient-A to dress, go to the bathroom and sit on the toilet seat for $10 \mathrm{~s}$. Then Patient-

155 A would dress, flush the toilet, perform handwashing with soap and water, open the bathroom

156 door and go back to bed. Immediately after this sequence, we took swabs of Patient-A's

157 subgluteal skin as well as from the toilet seat, tap handle, flush plate, and bathroom door

158 handle. Subsequently, Patient-B was asked to perform the same toilet use sequence as

159 Patient-A. We again took samples from the predefined Patient-B and environmental

160 swabbing sites. Then, the researcher left the ward asking both patients to behave as usual.

161 After an eight-hour interval, the researcher returned to the ward and sampled both

162 patients' hands and three predefined environmental sites for each patient (i.e., bed control

163 unit, phone, the personal entertainment device that the patient reported to have mainly used

164 among laptop, e-reader, tablet, hospital-bedside TV, and intravenous pump). Keyboards and

165 mobile phones of the nurse and the physician intern in charge of Patient-A and Patient-B

166 were swabbed accordingly (Table 1).

167

\section{Mobile device experiment}

To investigate whether SPED transmit from one patient to another through HCW mobile phones, we conceived an additional quasi-realistic experiment with the help of healthy volunteers.

Four volunteers performed a standardized scenario as Patient-A', Patient-B', DoctorA, and Doctor-B in a simulated two-bed hospital room involving personal stethoscopes and a single shared mobile phone (Figure 2), repeated as Run-1' and Run-2' using SPED-3 and SPED-2, respectively. SPED were deployed on Patient-A's wrist, chest, and neck. Then, Doctor-A examined Patient-A', answered the mobile phone, which was consequently used by Doctor-B, who in turn examined Patient-B'. Before SPED deployment and after, the experiment swabs were taken from the patients' wrists, neck and chest, both doctors' hands 
178 and cheeks, and both stethoscopes as well as the front and back of the mobile phone

179 (Table 2).

180 Results

181 Explorative experiments

182 Both explorative experiments successfully established transmission signals with the

183 applied SPED amount and concentration from human skin to inanimate surfaces and back to

184 skin (Figure 3). After testing different cleaning processes, we found a thorough cleaning

185 process using water and a household detergent (Oekoplan, Coop) eliminating SPED

186 (Figure 3).

187

188

189

190

191

192

193

194

195

196

197

198

\section{Patient experiment}

Overall, 133 swabs were collected during Run-1 to Run-3. The highest concentrations for 60 negative control samples before SPED deployment for Run-1, Run-2, and Run-3 were $3.01 \times 10^{-08} \mathrm{mg} / \mathrm{mL}$ (SPED 3), $9.55 \times 10^{-09} \mathrm{mg} / \mathrm{mL}$ (SPED 2) and $8.21 \times 10^{-09} \mathrm{mg} / \mathrm{mL}$ (SPED-

1), respectively, serving as run-specific positivity thresholds. Of the remaining 73 samples, 59 $(80.8 \%$ ) were positive (Figure 4$)$. Although the recovered SPED followed the logic of reduced concentrations with multiple touching sequences, there were considerable quantitative differences between the runs. Over all three runs, positivity rates were $100 \%$ on subgluteal skin, toilet seats, tap handles, and entertainment device controls, Patient-A's hands; $83.3 \%$ on patient phones and bed controls; $80 \%$ on intravenous pumps; $75 \%$ on toilet flush plate and door handle, $66.6 \%$ on doctor's keyboards; and $33.3 \%$, on nurses' or doctors' phones, nurse's keyboards, and $0 \%$ on Patient-Bs' hands. 
Overall, 56 samples were collected. Positivity thresholds in 28 baseline samples were $7.36 \times 10^{-7} \mathrm{mg} / \mathrm{mL}$ (SPED-3) and 1.63E x 10-7 mg/mL (SPED-2) for Run-1' and Run-2', respectively. The baseline sample of Doctor-A's hands in Run-1' was accidently contaminated and ignored. Of the 22 post-experiment samples, not including the initial SPED deposition sites on Patient A', 16 (72.7\%) tested positive for SPED (Figure 5).

\section{Discussion}

After Scotoni et al. (25) explored SPED transmission in the laboratory and found their behaviour to be similar to that of bacteria, the current study employed SPED for the first time in a real-life hospital environment. After establishing the method of skin contamination and sampling, we found SPED transmission from one patient to another via toilet use and spread to patient surroundings as far as distant HCWs' mobile phones and keyboards consistently over all runs. An additional off-site experiment confirmed that HCW mobile phones indeed transmitted SPED between patients.

The patient experiment indicated SPED spreading from Patient-A's subgluteal skin region to the toilet seat and from there to the subgluteal region of the roommate Patient-B. In addition, Patient-A contaminated the toilet flush plate, tap handle, and door handle with their hands with SPED which were acquired from a contaminated body part or environmental site beforehand. Patient-B became contaminated on the subgluteal skin site by exposure to the toilet seat. Of note, SPED were detected on the door handle in most of the cases, even though touching of the door handle occurred after handwashing in the study scenario. This implies that SPED had not been completely removed by handwashing. This contrasts the findings of Scotoni et al. (25) who investigated handwashing under laboratory conditions, but it 
positively simulates insufficient handwashing after toilet usage that has frequently been reported as typical population behaviour (43).

Eight hours after initial exposure, SPED have found their way to many surfaces in the immediate surroundings of the two patients and, in some instances reached the mobile phones and keyboards of the HCWs in charge of the patients, far from their room. Although SPED were always detectable on Patient-As' hands, swabs of Patient-Bs' hands were consistently negative. Nevertheless, SPED were found on all entertainment devices swabbed during the experiment, indicating a relevant but transient contamination of the patient's hands. Swabs of

Patient-A's bed position controls, phones, entertainment devices, and intravenous pumps were uniformly positive, as were most swabs of Patient-Bs' bed position controls, phones, and intravenous pumps. Patient-B tended to show lower SPED levels than Patient-A, consistent with the logic of a dilution effect over propagated spreading along a multi-touch transmission pathway (Figure 4). The lower SPED concentration found on flush plates could be explained by an uneven distribution of SPED over the hands and the way toilet handles were touched, as shown by Scotoni et al. before (25). Intravenous pumps, which are typically only operated by nurses, showed a positive signal for SPED in $80 \%$. This echoes the findings by Huslage et al. (42), who considered these devices as "high-touch" surfaces and implied HCW hands as transmission hubs. Alternatively, but less likely, patients touched their intravenous pump themselves. Pathogens found on toilet seats are often of faecal or skin origin including Escherichia. coli, sensitive Enterococci, VRE, and methicillin-resistant Staphylococcus aureus (MRSA) $(44,45)$. Toilet seats have been suspected as culprits for VRE transmission 244 (23) and individually attributed toilets have been associated with the control of VRE outbreaks $(46,47)$. Transmission via toilet seats was, however, never formally investigated.

246 Our results strongly support the presumable transmission of pathogens through a shared toilet 247 seat. 
Because we found a relevant concentration of SPED on a doctor's mobile phone far

249 from the study patients' room and because mobile devices are increasingly used at the

250 bedside, we decided to design a quasi-realistic patient care scenario that guaranteed SPED

251 could only reach the second patient through the mobile phone. The different contamination

252 levels found on the phone's screen and back, again indicate the translation of hand touching

253 into SPED detection patterns. Of note, the well-known risk of pathogen transmission through

254 stethoscopes was echoed in this experiment by a higher SPED load. Thakur et al. (27) equally

255 found stethoscopes to transmit a surrogate marker and MRSA. Thus, we agree with other

256 authors who have suggested targeted cleaning of stethoscopes $(48,49)$ and phones $(50-52)$

257 before.

This study has limitations. First, the number of conducted experiments did not allow to

perform comparative statistics. Our goal was to use SPED for the first time in a real-life hospital setting and outbreak situation and to test if toilet seats need indeed to be considered

in the spread of VRE or other potentially multi-drug resistant enteric flora. Second, as is the case with other surrogate tracers (27), habitual disinfection products do not inactivate SPED, while thorough cleaning with detergent and water does. This precludes mimicking real-life transmission perfectly, but instead allows to trace potential transmission pathways in the absence of disinfection procedures or, as our patient experiment shows, with the flawed execution of cleaning and disinfection procedures as it is often observed in real life. Further development of the SPED technology rendering the particles sensitive to disinfection agents might be feasible. Third, the extent of the spread of SPED ultimately depends on the quantity initially applied, but as Otter et al. (12) stated, the presence of pathogens at any concentration carries a risk for a transmission. Furthermore, the interpretation of relative quantity of recovered SPED must be taken with caution, since it depends on many factors including the

272 swabbing technique. This does, however, not interfere with the discovery of transmission 273 pathways. Fourth, by which intermediate transmission steps SPED reach the detection sites 
274 (e.g., the doctor's keyboard or mobile phone) remains unknown. Therefore, time intervals and 275 swabbing sites must be determined based on an initial hypothesis. Resolution can be increased 276 by increasing the number of swabbing sites and rates as did Oelberg et al. (26), or by adding 277 targeted evaluations as in our mobile device experiment.

\section{Conclusion}

In conclusion, SPED spread between patients through shared toilet use in a two-bed

280 patient room, starting from a small, contaminated skin area in one patient. This finding

281 highlighted the need for a reliable cleaning protocol, specifically as a potentially successful

282 control element of an ongoing VRE outbreak. Intravenous pumps, mobile phones, and

283 stethoscopes equally qualify as transmission hubs. And finally, the well-established

284 transmission risk associated with patients' and HCWs' hands was confirmed. With this study,

285 SPED were successfully applied in a real-life healthcare environment for the first time. Future

286 development of the SPED tracer system could attempt to render SPED sensitive to common

287 disinfection procedures and combine them with automated registration of human activity to 288 increase natural fidelity.

\section{List of abbreviations}

290 aOR: adjusted odds ratio

291 HCAI: healthcare associated infections

292 HCW: healthcare worker

293 HCWH: healthcare worker's hands

294 HH: hand hygiene

$295 \mathrm{mQ}$ water: ultrapure MilliQ water (type $1,18.2 \mathrm{M} \Omega \cdot \mathrm{cm}$ at $24^{\circ} \mathrm{C}$, Milli-Q ${ }^{\circledR}$; Merck, Darmstadt, Germany) 
297 MRSA: methicillin-resistant Staphylococcus aureus

298 qPCR: quantitative polymerase-chain-reaction

299 SPED: $\quad$ silica particles with encapsulated DNA

300 VRE: vancomycin-resistant enterococci

301 Declarations

302 Ethics approval and consent to participate

303 The Ethics Board of the Canton of Zurich reviewed the study protocol and formally

304 waved the necessity for a full ethics review based on the Swiss Law on Research on Humans

305 [BASEC-Nr. Req-2020-00974].

306

307 Consent for publication

308 Not applicable

310 Availability of data and materials

311 The datasets analysed during the current study are available from the corresponding author on

312 reasonable request.

\section{Competing interests}

RNG declares a financial interest as a shareholder of Haelixa AG, Kemptthal,

316 Switzerland. IP on DNA encapsulated into silica nanoparticles is licensed to Haelixa AG. All

317 other authors have no conflicts of interest. HS reports a travel grant and speaker's honorary

318 from AstraZeneca in 2020 and speaker honorary from agfam (non-profit) and Livinguard AG

319 in 2021 not related to this work. 
The study did not receive dedicated funding.

\section{Authors' contributions}

CU, HS, RNG and AML conceptualized and designed the study. JK synthesized the SPED and took an advisory role in planning the field experiments and in improving the sampling technique. AML and CU took explorative experiments in the lab, planned the field experiments, and conducted in-lab-preparations before all field experiments.

CU conducted all field experiments. CU and AML analysed all samples in the laboratory gaining raw data. AML performed particle characterization, optimized the qPCR protocol, and acquired the calibration curves. CU processed the raw data. CU, AML and HS evaluated the data. CU and AML drafted and finalised the manuscript; AML supplemented the technical aspects. HS and RNG took an advisory role during manuscript revision. All authors read and approved the final manuscript.

\section{Acknowledgments}

We would like to warmly thank all volunteers, patients, nurses, and physicians who participated in this study. We also want to express our special gratitude to Manuela Scotoni for her advice, and to Sarah York who proofread our manuscript as native English speaker.

\section{References}

342 1. WHO. Report on the Endemic Burden of Healthcare-Associated Infection

343 Worldwide. Geneva, Switzerland: World Health Organization; 2011.

344 2. WHO Guidelines on Hand Hygiene in Health Care: First Global Patient Safety

345 Challenge Clean Care Is Safer Care. 2009.

346 3. O'Neill J. Antimicrobial resistance antimicrobial resistance: tackling a crisis for the 347 health and wealth of nations. 2014. 
4. Buetti N, Wassilew N, Rion V, Senn L, Gardiol C, Widmer A, et al. Emergence of vancomycin-resistant enterococci in Switzerland: a nation-wide survey. Antimicrob Resist Infect Control. 2019;8:16.

351 5. Thierfelder C, Keller PM, Kocher C, Gaudenz R, Hombach M, Bloemberg GV, et al. 352 Vancomycin-resistant Enterococcus. Swiss Med Wkly. 2012;142:w13540.

353 6. Widmer AF. Vancomycin-resistant enterococci: an ongoing challenge for infection 354 control. Swiss Med Wkly. 2012;142:w13554.

355 7. Pittet D, Allegranzi B, Sax H, Dharan S, Pessoa-Silva CL, Donaldson L, et al. 356 Evidence-based model for hand transmission during patient care and the role of improved 357 practices. Lancet Infect Dis. 2006;6(10):641-52.

358 8. Sax H, Allegranzi B, Uçkay I, Larson E, Boyce J, Pittet D. 'My five moments for hand 359 hygiene': a user-centred design approach to understand, train, monitor and report hand 360 hygiene. J Hosp Infect. 2007;67(1):9-21.

3619 9. Gould DJ, Moralejo D, Drey N, Chudleigh JH. Interventions to improve hand hygiene 362 compliance in patient care. Cochrane Database Syst Rev. 2010(9):Cd005186.

363 10. Clack L, Scotoni M, Wolfensberger A, Sax H. "First-person view" of pathogen 364 transmission and hand hygiene - use of a new head-mounted video capture and coding tool. 365 Antimicrob Resist Infect Control. 2017;6:108.

366 11. Otter JA, Yezli S, Salkeld JA, French GL. Evidence that contaminated surfaces 367 contribute to the transmission of hospital pathogens and an overview of strategies to address 368 contaminated surfaces in hospital settings. Am J Infect Control. 2013;41(5 Suppl):S6-11.

369 12. Otter JA, Yezli S, French GL. The role played by contaminated surfaces in the 370 transmission of nosocomial pathogens. Infect Control Hosp Epidemiol. 2011;32(7):687-99.

371 13. Wolfensberger A, Clack L, Kuster SP, Passerini S, Mody L, Chopra V, et al. Transfer 372 of pathogens to and from patients, healthcare providers, and medical devices during care 
activity-a systematic review and meta-analysis. Infect Control Hosp Epidemiol. 2018;39(9):1093-107.

14. Ray AJ, Hoyen CK, Taub TF, Eckstein EC, Donskey CJ. Nosocomial transmission of vancomycin-resistant enterococci from surfaces. JAMA. 2002;287(11):1400-1.

15. Drees M, Snydman DR, Schmid CH, Barefoot L, Hansjosten K, Vue PM, et al. Prior environmental contamination increases the risk of acquisition of vancomycin-resistant enterococci. Clin Infect Dis. 2008;46(5):678-85.

16. Huang SS, Datta R, Platt R. Risk of acquiring antibiotic-resistant bacteria from prior room occupants. Arch Intern Med. 2006;166(18):1945-51.

17. Weber DJ, Anderson D, Rutala WA. The role of the surface environment in healthcare-associated infections. Current Opinion in Infectious Diseases. 2013;26(4). 18. Stiller A, Salm F, Bischoff P, Gastmeier P. Relationship between hospital ward design and healthcare-associated infection rates: a systematic review and meta-analysis. Antimicrob Resist Infect Control. 2016;5:51.

19. McDonald EG, Dendukuri N, Frenette C, Lee TC. Time-Series Analysis of Health Care-Associated Infections in a NewHospital With All Private Rooms. JAMA Intern Med. 2019;179(11):2019. p. 1501-6.

20. Duckro AN, Blom DW, Lyle EA, Weinstein RA, Hayden MK. Transfer of vancomycin-resistant enterococci via health care worker hands. Arch Intern Med. 2005;165(3):302-7.

21. Hayden MK, Blom DW, Lyle EA, Moore CG, Weinstein RA. Risk of hand or glove contamination after contact with patients colonized with vancomycin-resistant enterococcus or the colonized patients' environment. Infect Control Hosp Epidemiol. 2008;29(2):149-54. 22. Randle J, Arthur A, Vaughan N. Twenty-four-hour observational study of hospital hand hygiene compliance. J Hosp Infect. 2010;76(3):252-5. 
399 Environmental Panels as a Proxy for Nursing Facility Patients With Methicillin-Resistant 400 Staphylococcus aureus and Vancomycin-Resistant Enterococcus Colonization. Clin Infect 401 Dis. 2018;67(6):861-8.

402 24. Giannini MA, Nance D, McCullers JA. Are toilet seats a vector for transmission of 403 methicillin-resistant Staphylococcus aureus? Am J Infect Control. 2009;37(6):505-6.

404 25. Scotoni M, Koch J, Julian TR, Clack L, Pitol AK, Wolfensberger A, et al. Silica 405 nanoparticles with encapsulated DNA (SPED) - a novel surrogate tracer for microbial 406 transmission in healthcare. Antimicrob Resist Infect Control. 2020;9(1):152.

407 26. Oelberg DG, Joyner SE, Jiang X, Laborde D, Islam MP, Pickering LK. Detection of 408 pathogen transmission in neonatal nurseries using DNA markers as surrogate indicators.

409 Pediatrics. 2000;105(2):311-5.

410 27. Thakur M, Alhmidi H, Cadnum JL, Jencson AL, Bingham J, Wilson BM, et al. Use of 411 viral DNA surrogate markers to study routes of transmission of healthcare-associated 412 pathogens. Infect Control Hosp Epidemiol. 2020:1-6.

413 28. Alhmidi H, Cadnum JL, Jencson AL, Gweder AA, Donskey CJ. Sharing is not always 414 a good thing: Use of a DNA marker to investigate the potential for ward-to-ward 415 dissemination of healthcare-associated pathogens. Infect Control Hosp Epidemiol. $416 \quad 2019 ; 40(2): 214-6$.

417 29. Alhmidi H, John A, Mana TC, Koganti S, Cadnum JL, Shelton MB, et al. Evaluation 418 of Viral Surrogate Markers for Study of Pathogen Dissemination During Simulations of 419 Patient Care. Open Forum Infect Dis. 2017;4(3):ofx128.

420 30. John A, Alhmidi H, Cadnum JL, Jencson AL, Donskey CJ. Contaminated Portable 421 Equipment Is a Potential Vector for Dissemination of Pathogens in the Intensive Care Unit. 422 Infect Control Hosp Epidemiol. 2017;38(10):1247-9. 
424 of a nonpathogenic viral DNA surrogate marker from high-touch surfaces in rooms of longterm care facility residents. Am J Infect Control. 2017;45(10):1165-7.

32. Koganti S, Alhmidi H, Tomas ME, Cadnum JL, Jencson A, Donskey CJ. Evaluation of Hospital Floors as a Potential Source of Pathogen Dissemination Using a Nonpathogenic Virus as a Surrogate Marker. Infect Control Hosp Epidemiol. 2016;37(11):1374-7.

33. Tomas ME, Cadnum JL, Mana TS, Jencson AL, Koganti S, Alhmidi H, et al. Utility of a Novel Reflective Marker Visualized by Flash Photography for Assessment of Personnel

431 Contamination During Removal of Personal Protective Equipment. Infect Control Hosp 432 Epidemiol. 2016;37(6):711-3.

433 34. Alhmidi H, Li DF, Cadnum JL, Haq MF, Pinto-Herrera NC, Wilson BM, et al. Use of 434 simulations to evaluate the effectiveness of barrier precautions to prevent patient-to-patient 435 transfer of healthcare-associated pathogens. Infection Control \& Hospital Epidemiology. $436 \quad 2020: 1-6$.

437 35. Alhmidi H, Koganti S, Tomas ME, Cadnum JL, Jencson A, Donskey CJ. A pilot study 438 to assess use of fluorescent lotion in patient care simulations to illustrate pathogen 439 dissemination and train personnel in correct use of personal protective equipment. Antimicrob $440 \quad$ Resist Infect Control. 2016;5:40.

441 36. Paunescu D, Puddu M, Soellner JO, Stoessel PR, Grass RN. Reversible DNA 442 encapsulation in silica to produce ROS-resistant and heat-resistant synthetic DNA 'fossils'. 443 Nat Protoc. 2013;8(12):2440-8.

444 37. Grass RN, Schälchli J, Paunescu D, Soellner JOB, Kaegi R, Stark WJ. Tracking Trace 445 Amounts of Submicrometer Silica Particles in Wastewaters and Activated Sludge Using 446 Silica-Encapsulated DNA Barcodes. Environmental Science \& Technology Letters. $447 \quad 2014 ; 1(12): 484-9$. 
38. Bloch MS, Paunescu D, Stoessel PR, Mora CA, Stark WJ, Grass RN. Labeling milk

449 along its production chain with DNA encapsulated in silica. J Agric Food Chem. 2014;62(43):10615-20.

39. Mora CA, Paunescu D, Grass RN, Stark WJ. Silica particles with encapsulated DNA as trophic tracers. Mol Ecol Resour. 2015;15(2):231-41.

40. Mikutis G, Deuber CA, Schmid L, Kittila A, Lobsiger N, Puddu M, et al. SilicaEncapsulated DNA-Based Tracers for Aquifer Characterization. Environ Sci Technol. 2018;52(21):12142-52.

41. Croissant JG, Fatieiev Y, Khashab NM. Degradability and Clearance of Silicon, Organosilica, Silsesquioxane, Silica Mixed Oxide, and Mesoporous Silica Nanoparticles. Advanced Materials. 2017;29(9):1604634.

42. Huslage K, Rutala WA, Sickbert-Bennett E, Weber DJ. A quantitative approach to defining "high-touch" surfaces in hospitals. Infect Control Hosp Epidemiol. 2010;31(8):8503.

43. Drankiewicz D, Dundes L. Handwashing among female college students. American Journal of Infection Control. 2003;31(2):67-71.

44. Shams AM, Rose LJ, Edwards JR, Cali S, Harris AD, Jacob JT, et al. Assessment of the Overall and Multidrug-Resistant Organism Bioburden on Environmental Surfaces in Healthcare Facilities. Infect Control Hosp Epidemiol. 2016;37(12):1426-32.

Reduction of Clostridium Difficile and vancomycin-resistant Enterococcus contamination of 469 environmental surfaces after an intervention to improve cleaning methods. BMC Infect Dis. 2007;7:61.

471 46. Pearman JW. 2004 Lowbury Lecture: the Western Australian experience with

472 vancomycin-resistant enterococci - from disaster to ongoing control. J Hosp Infect. 63.

473 England2006. p. 14-26. 
474 47. Vuichard-Gysin D, Schlegel, M.Troillet, N.Senn, L.Marschall, J.Blanc, D.S. Buetti, N.

475 Egli, A., Kuster SK, A. Balmelli, C. Sommerstein, R. Nartey, L. Masserey Spicher, V.

476 Gardiol, C., Widmer AF, Harbarth S. Eindämmung der Verbreitung von Vancomycin-

477 resistenten Enterokokken (VRE) in der Schweiz: Aktualisierung der nationalen

478 Empfehlungen. VRE task force, on behalf of Swissnoso; 2019.

479 48. Longtin Y, Schneider A, Tschopp C, Renzi G, Gayet-Ageron A, Schrenzel J, et al.

480 Contamination of Stethoscopes and Physicians' Hands After a Physical Examination. Mayo

481 Clinic Proceedings. 2014;89(3):291-9.

482 49. O'Flaherty N, Fenelon L. The stethoscope and healthcare-associated infection: a snake 483 in the grass or innocent bystander? Journal of Hospital Infection. 2015;91(1):1-7.

484 50. Brady RRW, Wasson A, Stirling I, McAllister C, Damani NN. Is your phone bugged? 485 The incidence of bacteria known to cause nosocomial infection on healthcare workers' mobile 486 phones. Journal of Hospital Infection. 2006;62(1):123-5.

487 51. Simmonds R, Lee D, Hayhurst E. Mobile phones as fomites for potential pathogens 488 in hospitals: microbiome analysis reveals hidden contaminants. Journal of Hospital Infection. 489 2020;104(2):207-13.

490 52. Martina PF, Martinez M, Centeno CK, Von Specht M, Ferreras J. Dangerous 491 passengers: multidrug-resistant bacteria on hands and mobile phones. Journal of preventive 492 medicine and hygiene. 2019;60(4):E293-E9. 


\begin{tabular}{cccc}
\hline $\begin{array}{c}\text { Sampling sites } \\
\text { before }\end{array}$ & $\begin{array}{c}\text { Sampling sites } \\
\text { immediately }\end{array}$ & $\begin{array}{c}\text { Sampling sites } \\
\text { after eight- }\end{array}$ \\
SPED at & sequence & \\
baseline & & \\
& & \\
\end{tabular}

\section{Patient skin}

\begin{tabular}{|c|c|c|c|}
\hline Subgluteal skin patient A & $\mathrm{X}$ & $\mathrm{X}$ & \\
\hline Hands/palms patient A & $X$ & & $\mathrm{X}$ \\
\hline Subgluteal skin patient B & $\mathrm{X}$ & $\mathrm{X}$ & \\
\hline Hands/palms patient B & $X$ & & $\mathrm{X}$ \\
\hline \multicolumn{4}{|l|}{ Restroom } \\
\hline Toilet seat after patient $\mathrm{A}$ & $X$ & $X$ & \\
\hline Flush plate after patient $A$ & $X$ & $X$ & \\
\hline Tap handle after patient $\mathrm{A}$ & $X$ & $X$ & \\
\hline Door handle after patient $\mathrm{A}$ & $\mathrm{X}$ & $X$ & \\
\hline Toilet seat after patient B & $\mathrm{X}$ & $\mathrm{X}$ & \\
\hline Flush plate after patient B & $\mathrm{X}$ & $X$ & \\
\hline Tap handle after patient B & $\mathrm{X}$ & $X$ & \\
\hline Door handle after patient B & $X$ & $X$ & \\
\hline
\end{tabular}

\section{Patient room}

Bed control patient A 


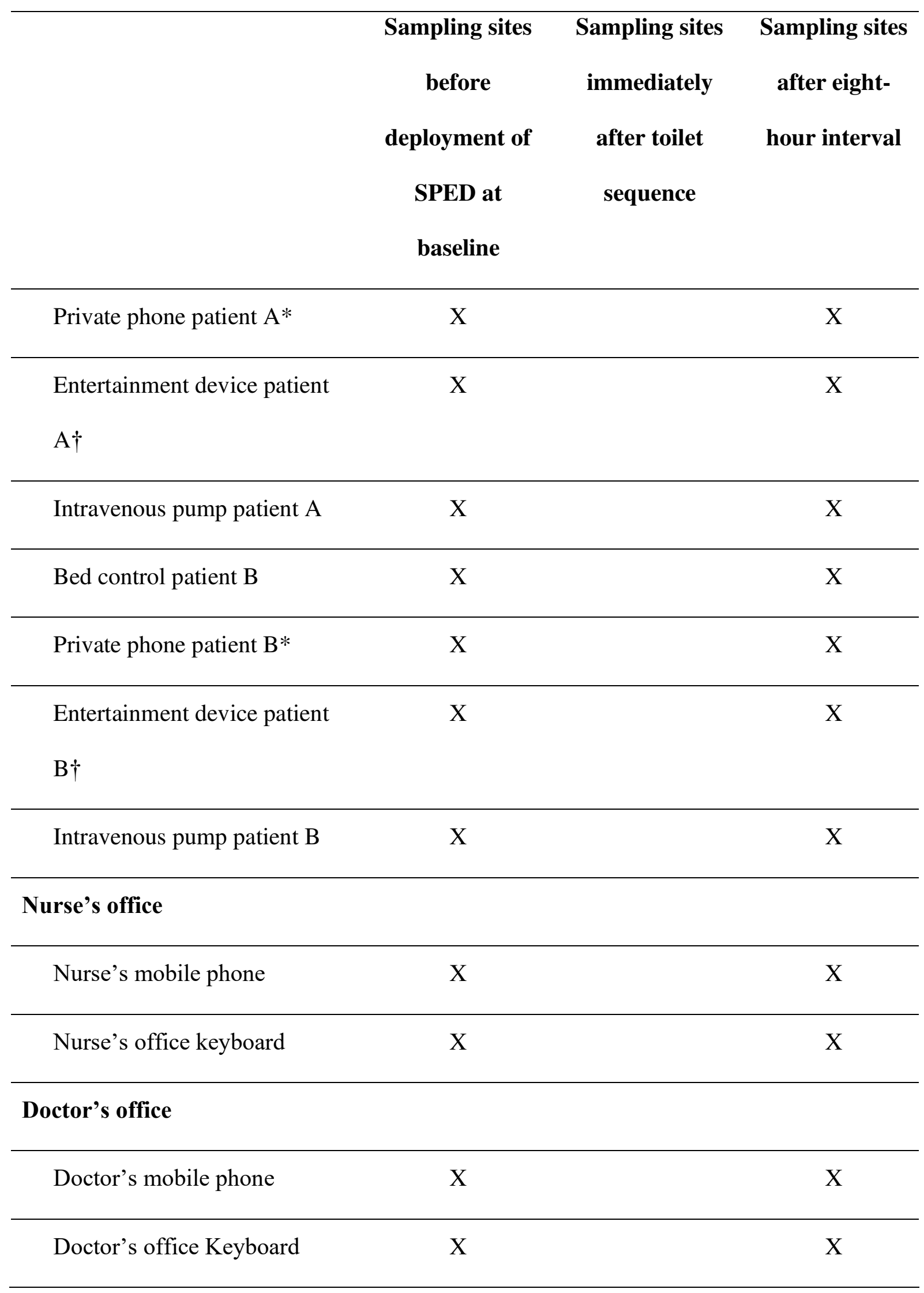

496 Legend: SPED, silica nanoparticles with encapsulated DNA 
497 * The patients' private mobile phone was swapped if available, otherwise the beside phone 498 provided by hospital.

$499 \dagger$ The most used device was assessed (among tablet, e-reader, laptop, hospital bedside TV):

500 Run 1) A: tablet, B: bedside hospital TV; Run 2) A: e-reader, B: bedside hospital TV; Run 3 )

501 A: tablet, B: bedside hospital TV 


\begin{tabular}{lcc}
\hline & $\begin{array}{c}\text { Swabbing sites before } \\
\text { deployment of SPED as }\end{array}$ & $\begin{array}{c}\text { Swabbing sites after } \\
\text { patient care }\end{array}$ \\
& baseline & \\
\hline Patient A' & & $\mathrm{X}$ \\
\hline Wrist, radial pulse point & $\mathrm{X}$ & $\mathrm{X}$ \\
\hline Neck, carotid pulse point & $\mathrm{X}$ & $\mathrm{X}$ \\
\hline Chest, Erb's point & $\mathrm{X}$ & \\
\hline Doctor A & $\mathrm{X}$ & $\mathrm{X}$ \\
\hline Cheek, phone touching point & $\mathrm{X}$ & $\mathrm{X}$ \\
\hline Hands, palms & $\mathrm{X}$ & $\mathrm{X}$ \\
\hline Stethoscope A, chest piece & & \\
\hline Wrist, radial pulse point & & \\
\hline Neck, carotid pulse point & & \\
\hline Chest, Erb's point & & \\
\hline
\end{tabular}

\section{Doctor B}

Cheek, phone touching point

Hands, palms

Stethoscope B, chest piece
$\mathrm{X}$

$\mathrm{X}$

X
X

X

X

\section{Mobile Phone}




\begin{tabular}{lcc}
\hline & Swabbing sites before & Swabbing sites after \\
deployment of SPED as & patient care \\
baseline & sequence \\
\hline Phone, frontside screen & $\mathrm{X}$ & $\mathrm{X}$ \\
\hline Phone, backside & $\mathrm{X}$ & $\mathrm{X}$ \\
\hline
\end{tabular}

503

504 Legend: SPED, silica nanoparticles with encapsulated DNA 

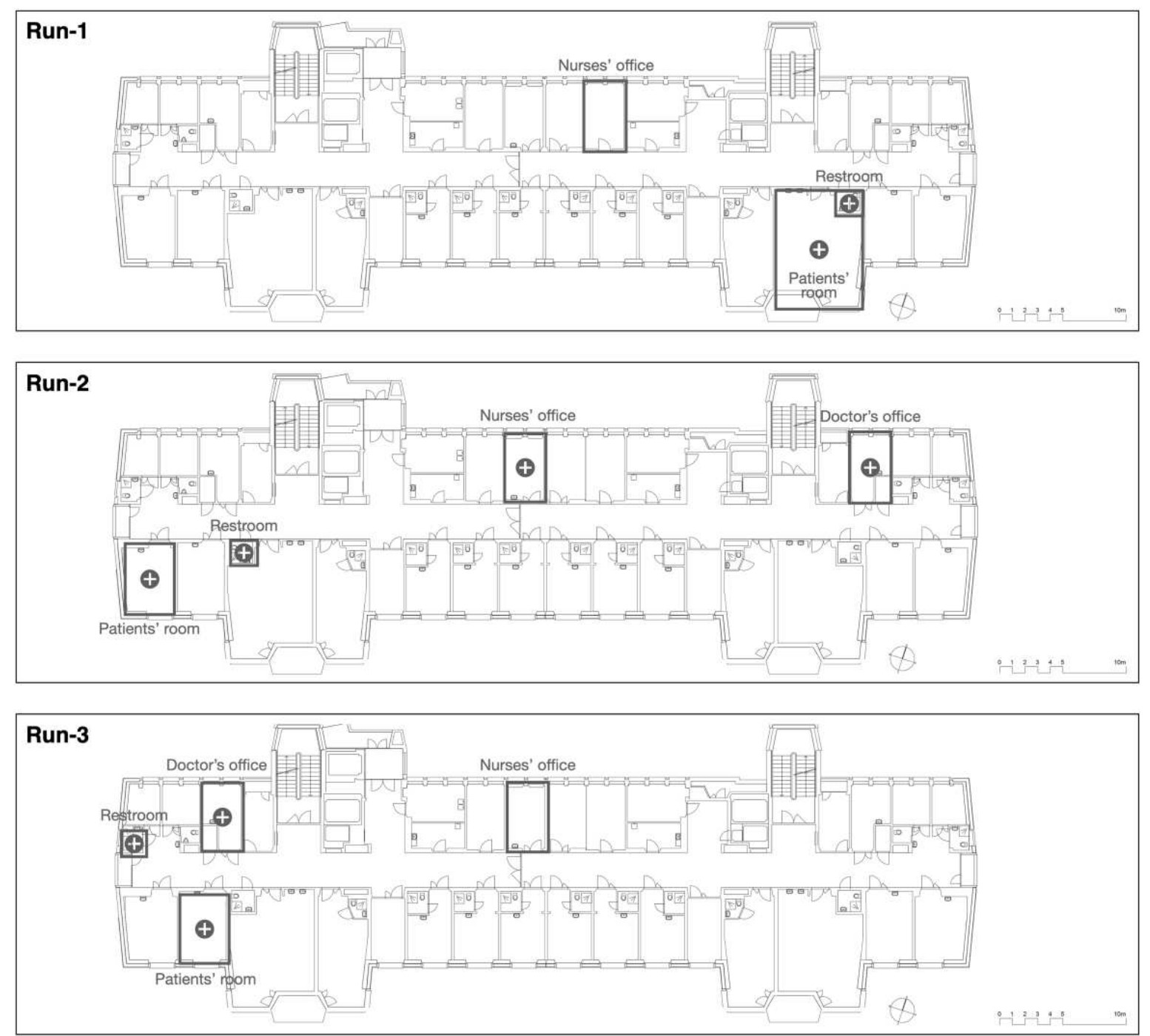

507 Legend: The floorplan shows the study ward three times (once for each study run) and the

508 localisation of the two-bed patient room, shared restroom, nurses' and doctor's office in the

509 study ward. In Run-1 the doctor's office was situated on another floor and does therefore not

510 appear in the floor plan. The plus signs indicate rooms with one or more positive SPED

511 swabbing results at 8-hour follow-up. Detailed swabbing sites s. Table 1.

512 SPED, silica nanoparticles with encapsulated DNA. 


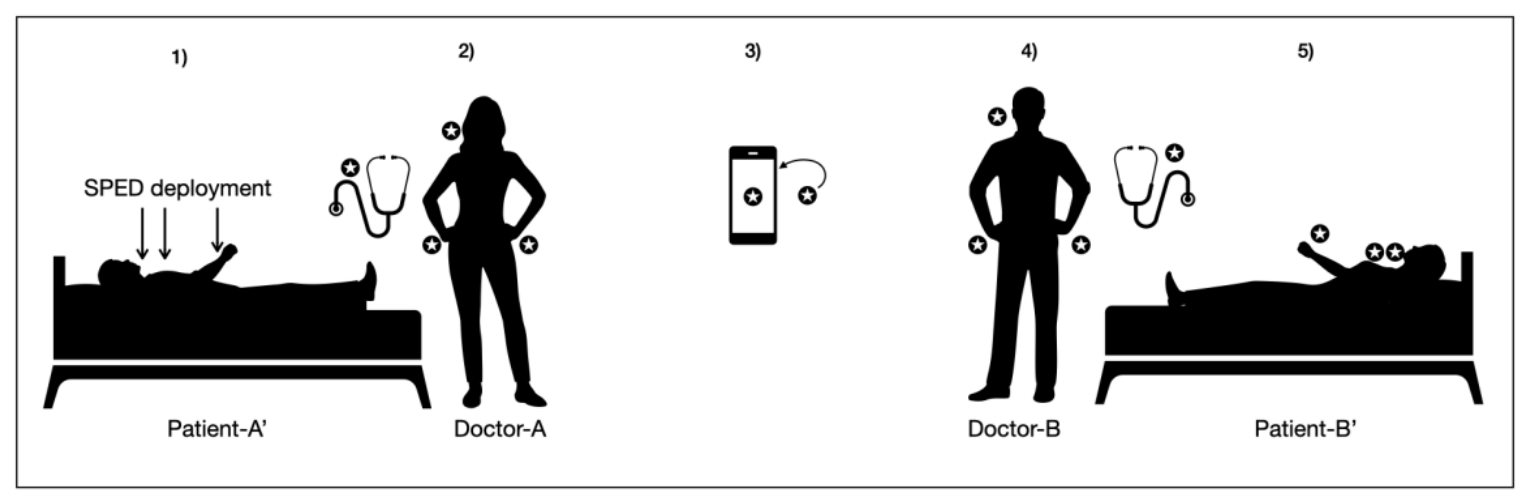

514

515 Legend: Scenarios plot: 1) Researcher deploys SPED on neck (A. carotis), chest (Erb's

516 point), and wrist (A. radialis) of Patient-A'; 2) Doctor-A listens to heart sounds and takes

517 radial pulse of Patient-A'; 3) Phone rings, Doctor-A takes the call for 30 seconds, then

518 leaves the experiment scene; 4) Phone rings again, Doctor-B takes the call for 30 seconds;

519 and 5) listens to heart sounds and takes radial pulse of Patient-B'. Star symbols indicate

520 SPED swabbing sites.

521 SPED, silica nanoparticles with encapsulated DNA. 


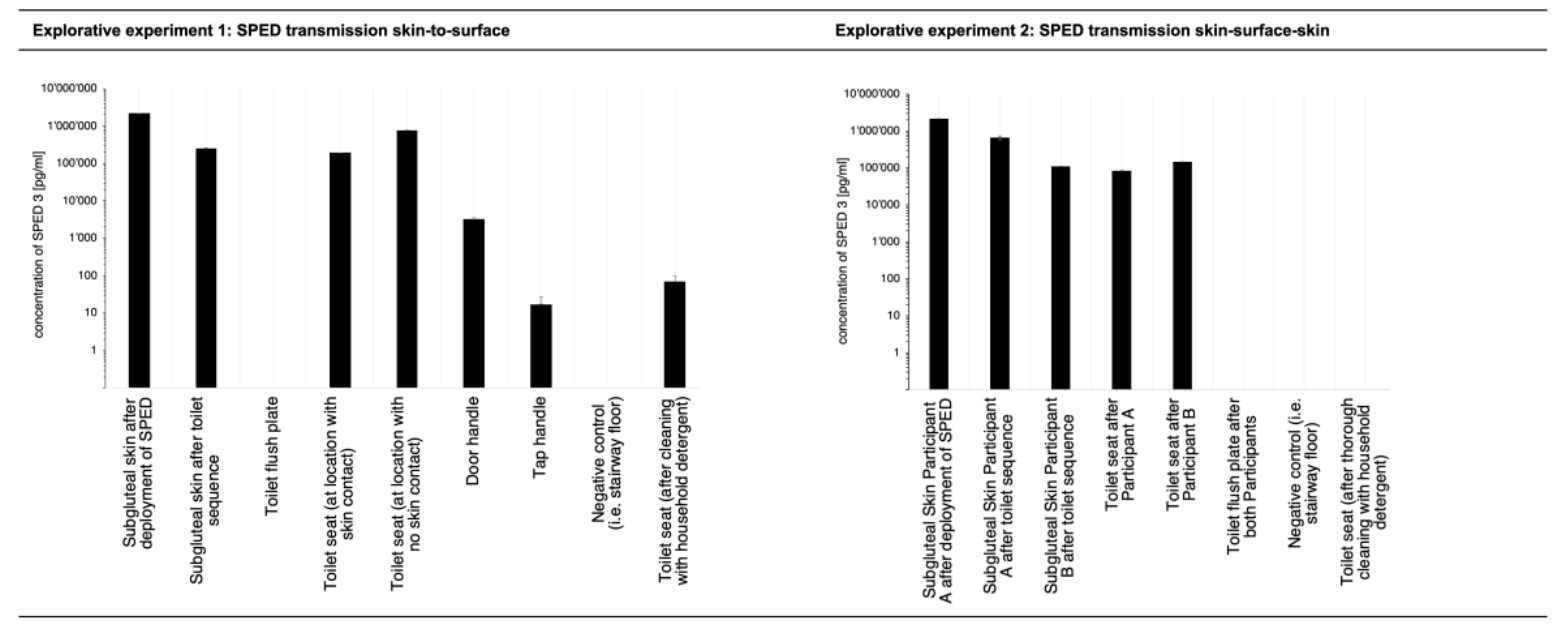

523

524 Legend: Explorative experiment 1: Transmission of SPED deployed to subgluteal human

525 skin to inanimate objects such as the toilet seat or the door handle through a standardized

526 toilet sequence; Explorative experiment 2: Transmission of SPED deployed on Participant-

527 A's subgluteal skin to Participant-B's subgluteal region through successive use of the same 528 toilet.

529 SPED, silica nanoparticles with encapsulated DNA. 


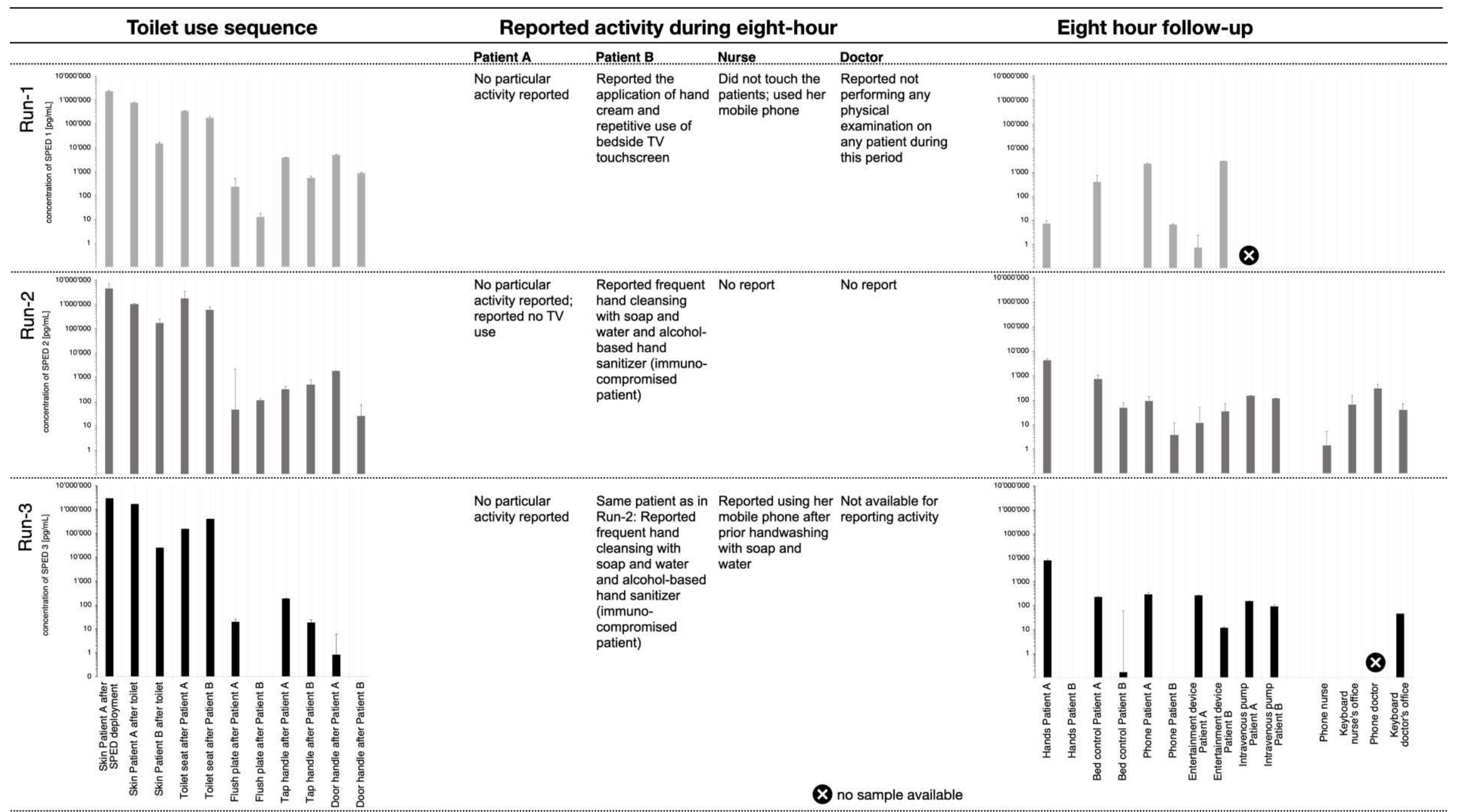


Figure 5. Results of the 'Mobile device experiment'
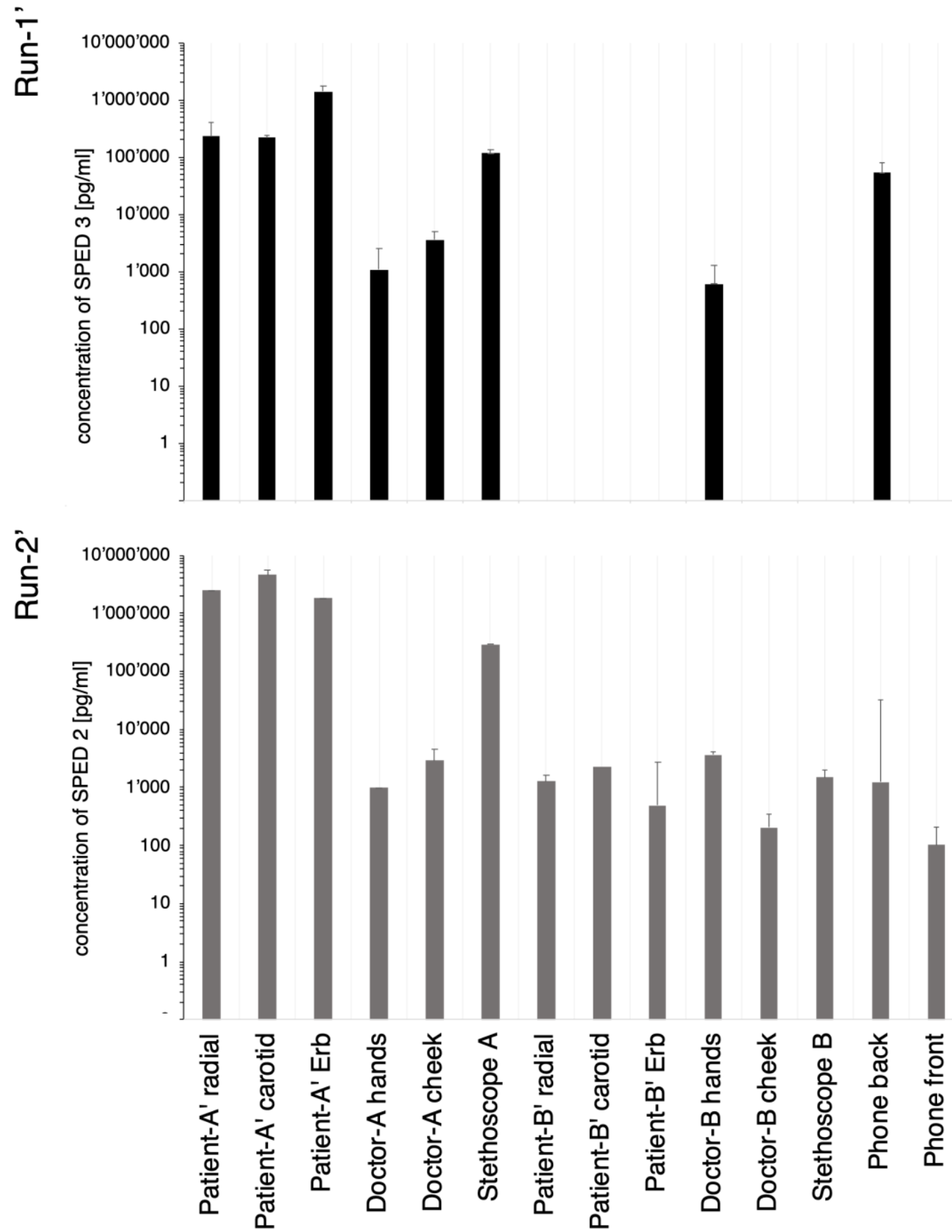

536 Legend: [NIL] 


\section{Appendix}

\section{Technical Appendix}

\section{DNA barcode sequences}

DNA barcodes were ordered as single strands at a length of 65 nucleotides, with $40 \%$ GC-content, as listed in Appendix Table 1. The sequences were synthesized by Microsynth AG (Balgach, Switzerland) and shipped in dried state. Previous to annealing, the single strands were dissolved in annealing buffer (Tris $10 \mathrm{mmol} / \mathrm{L} \mathrm{pH} \mathrm{7.5-8.0,} \mathrm{EDTA} 1 \mathrm{mmol} / \mathrm{L}$, $\mathrm{NaCl} 50 \mathrm{mmol} / \mathrm{L}$ ) to a final concentration of $5 \mathrm{~g} / \mathrm{L}$. For annealing, the single strands were mixed together in equal parts, treated at $95{ }^{\circ} \mathrm{C}$ for $5 \mathrm{~min}$ and slowly cooled down to room temperature.

\section{SPED synthesis}

Per batch of DNA encapsulation, 4 x $4 \mathrm{~mL}$ of silica nanoparticles $(110 \mathrm{~nm}, 50 \mathrm{mg} / \mathrm{mL}$ in isopropanol; Pinfire, Frankfurt a. M., Germany) were surface-functionalized in 4 falcon tubes. For functionalization, $40 \mu \mathrm{g}$ of $\mathrm{N}$-trimethoxysilylpropyl-N,N,N- trimethylammonium chloride (TMAPS) (50\% wt in methanol; abcr, Karlsruhe, Germany) were added, followed by 12 hours of shaking at room temperature, at 900 rotations per minute (rpm). Next, a $2 \mathrm{~mL}$ batch of $150 \mathrm{ng} / \mu \mathrm{L}$ of corresponding annealed DNA (sequences see Appendix Table 1) was added to $200 \mathrm{~mL}$ ultrapure water (mQ; type $1,18.2 \mathrm{M} \Omega \cdot \mathrm{cm}$ at $24^{\circ} \mathrm{C}$, Milli-Q®; Merck, Darmstadt, Germany), followed by adding $0.4 \mathrm{~g}$ of the functionalized particles and vortexing for 10 seconds. Subsequently, $4 \mu \mathrm{L}$ TMAPS were added, before vortexing and sonicating for 20 seconds. Then, $62.5 \mu \mathrm{L}$ of tetraethyl orthosilicate (TEOS) ( $\geq 99.0 \%$; Sigma-Aldrich, St. Louis, Missouri, USA) were added. The mixture was shaken for $5 \mathrm{~h}$ at $600 \mathrm{rpm}$. In a further step, $10 \mathrm{~mL}$ iPrOH and $5.9 \mathrm{~mL}$ TEOS were mixed with $484.1 \mathrm{~mL}$ ultrapure water and 
combined with the previous suspension. The batch was then stirred for 4 days at $600 \mathrm{rpm}$.

561 Three different batches were synthesized, each labeled with its own DNA barcode.

562

563

564

565

566

567

568

569

570

571

572

573

\section{SPED characterization}

DNA loading of the SPED batches was estimated by measurement of DNA concentration in solution before and after the reaction on a photometer (NanoDrop 2000c; Thermo Fisher Scientific, Waltham, Massachusetts, US), the difference being the amount of loaded DNA. Hydrodynamic size distributions of SPED in suspension $(\sim 2 \mathrm{mg} / \mathrm{mL}$ in $\mathrm{mQ}$ water $)$ were measured using a dispersion analyser (LUMiSizer, $470 \mathrm{~nm}$ light source; LUM GmbH, Berlin, Germany). Transmission profiles were recorded in time intervals of 5 seconds, at a rotational speed of 3000-4000 rpm, for $2 \mathrm{~h}$. Statistical data analysis was performed by SEPView ${ }^{\circledR}$ software provided with the dispersion analyser. For scanning electron microscopy (SEM), SPED were prepared at a concentration of $0.1 \mathrm{mg} / \mathrm{mL}$ in $\mathrm{iPrOH}$, loaded on a STEM C-grid and dried under infrared light. Imaging was performed on a NovaNanoSEM450 device (Field Electron and Ion Company, Hillsboro, Oregon, US) at a voltage of $20 \mathrm{kV}$.

\section{Recovery and processing of SPED}

In our experiments SPED were diluted in ultrapure MilliQ water (type $1,18.2 \mathrm{M} \Omega \cdot \mathrm{cm}$ at $24^{\circ} \mathrm{C}$, Milli-Q®; Merck, Darmstadt, Germany) to a working concentration of $1 \mathrm{mg} / \mathrm{mL}$, of which $3 \mathrm{~mL}$ were used for patient colonization. To detect SPED on skin or surfaces, a similar swabbing technique as established by Scotoni et al. (25) was applied. The swabbing technique included cotton swabs (Naturaline Wattestäbchen, Steinfels Swiss, Winterthur, Switzerland) premoistened in $20 \%$ glycerol solution $(99+\%$ Glycerol 1 L, VWR chemicals bvba, Leuven, Belgium; 20vol\% in mQ water) that were rolled three times over a pre-defined area and then added to $2 \mathrm{~mL}$ microcentrifugation tubes (Eppendorf AG, Hamburg, Germany) pre-filled with $200 \mu \mathrm{L} \mathrm{mQ}$ water and stored at room temperature. To fit the cotton swabs in the tubes, swabs 
were shortened with scissors. All samples were transported to the laboratory for further processing.

\section{Quantification of SPED}

The swabs obtained at the experimental site were stored at room temperature for a maximal duration of 14 hours before being processed. For subsequent SPED quantification, each sample was ultrasonicated for 15 min and briefly spun down in a minicentrifuge to clear the SPED from the cotton swab as much as possible. For the etching process 2 vol\% of buffered oxide etch, consisting of $0.03 \mathrm{wt} \%$ ammonium hydrogen difluoride $\left(\mathrm{NH}_{4} \mathrm{FHF}\right.$, pure; Merck, Darmstadt, USA) and 0.02 wt\% ammonium fluoride $\left(\mathrm{NH}_{4} \mathrm{~F}\right.$, puriss.; Sigma-Aldrich, St. Louis, Missouri, USA), was added to the sample liquid to release the DNA from the silica particles. All samples were ultrasonicated again for 15 min after adding BOE. The suspension was then analyzed by real-time quantitative PCR (LightCycler® 96, Roche Molecular Systems, Pleasanton, USA) with SYBR® Green Master Mix (KAPA SYBR FAST qPCR master mix universal (2x, Kapa Biosystems, cat. no. KK4601)). The qPCR total reaction volume was $20 \mu \mathrm{l}$ made up of $5 \mu \mathrm{l}$ sample solution, $1 \mu \mathrm{l}$ each of $10 \mu \mathrm{M}$ forward and reverse primer stock solutions (Microysynth AG, Balgach, Switzerland, Appendix Table 2), $10 \mu \mathrm{l}$ mastermix, and $3 \mu \mathrm{lmQ}$ water. The qPCR program contained a preincubation for $240 \mathrm{~s}$ at $95{ }^{\circ} \mathrm{C}$, followed by 40 cycles of a 3 -step amplification protocol $\left(2 \mathrm{~s}\right.$ at $95{ }^{\circ} \mathrm{C}, 12 \mathrm{~s}$ at $60{ }^{\circ} \mathrm{C}$, $4 \mathrm{~s}$ at $72{ }^{\circ} \mathrm{C}$ ). Technical triplicates were measured for each sample, using no-template controls as PCR negatives. Further calculations were based on qPCR cycle values (Cq value) provided by LightCycler96 Software standard protocol.

\section{Calculation of SPED concentration per sample}

To quantify the amount of SPED in each sample, calibration curves were measured.

For each batch of SPED used in our experiments a dilution series with 5 to 6 different 
608 concentrations $\left(10^{-3}, 10^{-4} \mathrm{mg} / \mathrm{mL}\right.$, etc. $)$ was measured to assign established particle

609 concentrations to the according cycle value from the qPCR.

610 The qPCR cycle values of the dilution series were plotted against the logarithmic

611 particle concentration (in $\mathrm{mg} / \mathrm{mL}$ resulting in a calibration curve. Use of linear regression of

612 the single log chart generates a curve in the form of $y=a x+b$ (y as the cycle value and $\mathrm{x}$ as

613 the ln of the concentration), consequently the concentration equals $\mathrm{e}^{\mathrm{y} / \mathrm{m}-\mathrm{b}}$.

614 The concentration of a given sample was calculated using the above formula with the

615 respective regression parameters (Appendix Table 3). Error bars are based on the standard

616 deviation of technical triplicates in qPCR data.

617 Evaluation of SPED and threshold

618 Prior to each experiment every sampling site was swabbed as a blank sample. The

619 blank sample with the lowest qPCR cycle value and thus, the highest load of SPED was used

620 as threshold for the according experiment. The cut-off value was calculated based on the

621 qPCR cycle value plus the standard deviation of the technical triplicates. Sample

622 concentration above threshold were considered as positive for SPED, values below as

623 negative.

624 Scanning electron microscopy SEM

625 SPED were prepared as a suspension of $0.1 \mathrm{mg} / \mathrm{mL}$ in 2-propanol, loaded on a STEM

626 C-grid and dried under infrared light. The samples were imaged on a NovaNanoSEM450

627 device (Field Electron and Ion Company, Hillsboro, Oregon, US) at a voltage of $20 \mathrm{kV}$ at

628 52480x magnification (Appendix Figure 1). 
Appendix Table 1. DNA sequences used for SPED synthesis

\begin{tabular}{|l|l|}
\hline Name & \multicolumn{1}{|c|}{ Sequence } \\
forward & TTCGAGGGTGAGTT \\
\hline SPED-1 & AACTCACCCTCGAATCGAAAAACGCAGGAACCTAACGACAACGAAGAGA \\
reverse & TCCTTAGAGCCCATAA \\
\hline SPED-2 & TATGCGCCTTTATACTCTTATAGGTATCCTGTTGCTGGCACTTTTTTCTAG \\
forward & CAAAGTCTTCTCCT \\
\hline SPED-2 & AGGAGAAGACTTTGCTAGAAAAAAGTGCCAGCAACAGGATACCTATAAG \\
reverse & AGTATAAAGGCGCATA \\
\hline SPED-3 & TAGCTCGTTCATAGAATCACTTCGCCGTACTCAACGTAGTGGTTTTTGTTT \\
forward & AGCTCAAACAGGTT \\
\hline SPED-3 & AACCTGTTTGAGCTAAACAAAAACCACTACGTTGAGTACGGCGAAGTGA \\
reverse & TTCTATGAACGAGCTA \\
\hline
\end{tabular}

630

631 
632 Appendix Table 2. Primer (forward and reverse) for each batch of SPED for qPCR

\begin{tabular}{|l|l|}
\hline GM-06-S1 (SPED-1) & $\begin{array}{l}\text { primer forward ATGGGCTCTAAGGATCTC } \\
\text { primer reverse CTCACCCTCGAATCGAA }\end{array}$ \\
\hline GM-06-S2 (SPED-2) & primer forward ATGCGCCTTTATACTCTTA \\
& primer reverse GGAGAAGACTTTGCTAGAA \\
\hline GM-06-S3 (SPED-3) & primer forward AGCTCGTTCATAGAATCAC \\
& primer reverse ACCTGTTTGAGCTAAACAA \\
\hline
\end{tabular}

633

634 
635 Appendix Table 3. Regression parameters for calculation of SPED concentration with the

636 formula: $\mathrm{y}=\mathrm{ax}+\mathrm{b}$ ( $\mathrm{y}$ as the cycle value and $\mathrm{x}$ as the $\ln$ of the concentration)

\begin{tabular}{|l|l|l|l|}
\hline Batch & a & $\mathrm{b}$ & $\mathrm{R}^{2}$ (coefficient of \\
& & & determination) \\
\hline SPED-1 & & & \\
\hline SPED-06-S1) & -1.404 & -4.429 & 0.994 \\
(GM-06-S2) & -1.645 & -5.397 & 0.999 \\
\hline SPED-3 & -1.852 & -6.345 & 0.999 \\
$($ GM-06-S3) & & & \\
\hline
\end{tabular}

637

638 
639 Appendix Figure 1. Scanning electron microscopy image of dried SPED

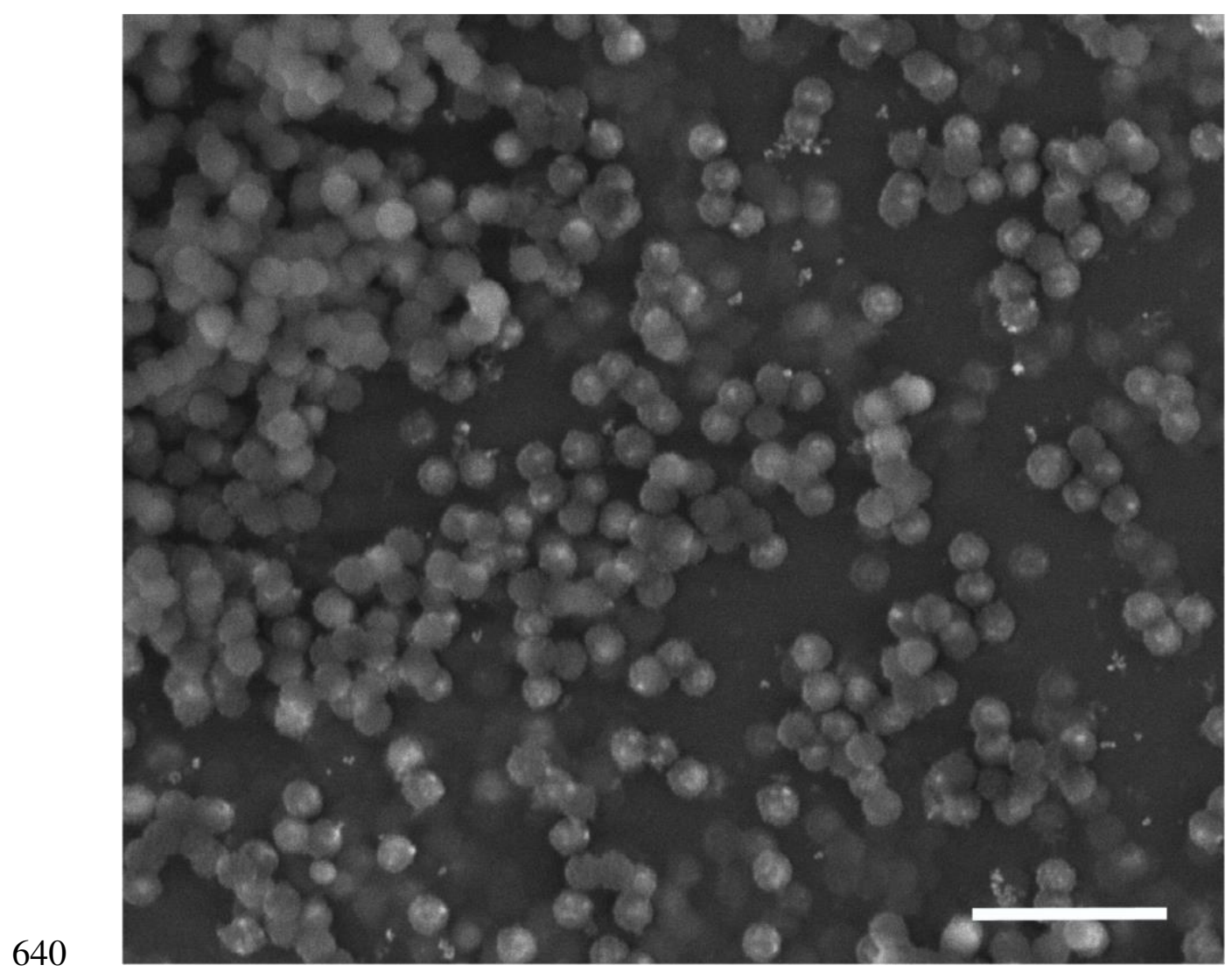

641 Legend: Scale bar indicates $500 \mathrm{~nm}$. 